\title{
АЛГОРИТМ И МЕТОД ВЫЯВЛЕНИЯ ОБСТРУКЦИОННЫХ ПРИЕМОВ В КОММУНИКАЦИЯХ В ИТ-ПРОЕКТАХ
}

\section{ALGORITHM AND METHOD FOR DETECTING OBSTRUCTIVE COMMUNICATION TECHNIQUES IN IT PROJECTS}

S. Smirnov

Summary. Less than a third of the world's projects are fully successful. As one of the key problems that actually kill projects, the problem of poorquality project communications is described in the literature. The paper presents the results of the analysis of several hundred communications of 48 projects in one area of activity in order to identify the methods of unfriendly communications that have a negative impact on the project, which was not previously described in the literature. For the first time, the methodology of communication analysis and analysis of a large sample of communications are described. The initial data for the analysis and the criteria for their selection are described. The most common methods of unfriendly communication in projects are identified.

Keywords: project management, project communications, project risks, obstructive techniques.

\section{Введение}

$\Pi$ о данным крупнейших мировых организаций, занимающихся исследованиями в области эффективности проектов, ежегодно в мире инициируется и выполняется несколько миллионов проектов общей стоимостью более триллиона долларов США. Менее трети из них завершаются успешно - созданием продукта или услуги с заказанными функциями или свойствами, в установленное время, в рамках согласованного бюджета. Более половины проектов считаются лишь условно успешными - полученные результаты лишь частично удовлетворяют заказчика и соответствуют изначальным параметрам задачи в части функциональности, сроков и стоимости. [1] В исследованиях [2-8] также отмечается выраженная связь между объемом проекта и вероятностью его успешного завершения: для небольших, или относительно небольших, проектов процент провала составляет 4-5\%; для больших проектов (стоимость трудозатрат проекта сто миллионов рублей и более) эта величина достигает уже $38 \%$.

По результатам анализа литературных источников можно сделать вывод о существенном влиянии эффек-

\author{
Смирнов Сергей Павлович \\ Аспирант, Российский технологический \\ университет МИРЭА (г. Москва); РМР, Руководитель \\ департамента управления проектами, ПАО \\ «Вымпелком» (2. Москва) \\ smirnov.s.p1@edu.mirea.ru
}

Аннотация. Менее трети мирового объема выполняемых проектов являются полностью успешными. В качестве одной из ключевых проблем, фактически убивающих проекты, в литературе описана проблема некачественных коммуникаций проекта. В работе представлены результаты анализа нескольких сотен коммуникаций 48 проектов одного направления деятельности с целью выявления приемов недружественных коммуникаций, оказывающих негативное влияние на проект, что ранее не описывалось в литературе. Впервые описана методика проведения анализа коммуникаций и анализ большой выборки коммуникаций. Описаны исходные данные для анализа и критерии их отбора. Выявлены наиболее часто встречающиеся методы недружественной коммуникации в проектах.

Ключевые слова: управление проектами, проектные коммуникации, риски проектов, обструкционные приемы.

тивности и результативности коммуникаций проекта на эффективность решения критичных задач проекта:

- определение целей и задач проекта и критериев успешности проекта [5][6];

- идентификация и выделение ресурсов на исполнение проекта [2][4];

- управление исполнением проекта [7];

- управление изменениями проекта [3][6];

- закрытие проекта [8].

При этом, необходимо отметить, что большинство применяемых методов и стандартов управления проектами [9][10][11] основываются на нечеткой логике, субъективных суждениях, а также навыках ведения переговоров у менеджера проекта, что создает отдельное множество рисков, связанных с возможной ошибкой в связи с невысокой результативностью коммуникаций, в том числе, в связи с невозможностью достижения консенсуса по ключевым вопросам - согласования образа необходимого результата, планирования работ, приоритетов задач, выделения ресурсов, управления рисками.

В то же время, в настоящее время наблюдается активная трансформация коммуникационных моделей и тех- 
ник. На первый план выходят подходы и модели коммуникаций как информационного конфликта. В работе [12] отмечается, что активно развивается «представление об информационном конфликте как совокупности коммуникативных средств воздействия двух и более противоборствующих систем на субъекта (индивидуального или коллективного) с целью изменения его поведения необходимым для манипулятора образом». То есть, фактически, мы говорим о нарастании объема недружественных коммуникаций, являющихся манипуляциями. Своевременное и точное выявление признаков недружественных коммуникаций становится определяющим фактором эффективности проектных коммуникаций и, как следствие, фактором эффективности выполнения проектов.

Цель настоящей статьи - представить результаты анализа выявленных практик нарушения коммуникаций в 48 проектах, выполненных в ИТ-подразделении Компании. В рамках обсуждения результатов рассмотрены приемы идентификации недружественных коммуникаций и предлагаемые методы их модерации, если таковые были идентифицированы, а также рекомендации по административным улучшения процессов управления и поддержки управления проектами.

\section{По ххолы и материалы}

Исходными данными для анализа явились записи встреч участников команд проектов, протоколы встреч, интервью с участниками встреч и менеджерами проектов, презентации для открытия проектов, статусные презентации, презентации для закрытия проектов, отчеты по проекту в системе поддержки управления проектами.

Выбор проектов осуществлялся по критерию - 100\% проектов, которые входили в одну конкретную программу проектов, для которой проводился анализ возможности улучшения качества ведения проектов, увеличения вероятности выполнения проекта в сроки, т.к. этот параметр оказывал существенное влияние на опосредованные затраты Компании.

Презентации для открытия проектов, статусные презентации и презентации для закрытия проектов анализировались в полном объеме: все существующие материалы. Протоколы встреч анализировались в полном объеме: все существующие протоколы.

Отчеты по проектам анализировались в полном объеме: все существующие материалы.

Из записей встреч для анализа отобрано примерно 30\% существующих записей. Критериями для отбора явились:
100\% встреч, для которых не найдено протокола встречи;

- 100\% встреч, для которых в протоколах выявлено несоответствие повестки и протокола встречи;

- 100\% встреч с числом участников более 10 .

- 25\% случайно отобранных записей встреч, не соответствующих вышеупомянутым критериям.

Интервью проводилось со всеми менеджерами проектов программы.

При интервью с менеджерами проектов обращалось внимание на методологию подготовки встречи:

- наличие четко определенной повестки встречи;

- идентификацию аудитории встречи;

- количество участников встречи;

- заблаговременное распространение повестки встречи;

- модерирование встречи;

- подготовку проекта решения встречи до проведения мероприятия.

Интервью с участниками встреч проводилось только для встреч, которые проводились не позднее чем за 1 неделю до момента проведения интервью.

При интервью с участниками встреч обращалось внимание на общее впечатление участников от встречи:

- были ли декларированы понятные цели и задачи встречи;

- достигнуты ли цели и задачи встречи;

- ощущения от качества общения (спокойное, нервное, позитивное, негативное);

При прослушивании записей встреч обращалось внимание на

- ознакомление участников встречи с целями и задачами встречи;

- факты непонимания участниками встречи своей роли или своих вопросов на встрече;

- управляемость встречи модератором;

- порядок высказываний;

- факты одновременного выступления, перекрикиваний (перебиваний);

- факты наличия нескольких одновременно дискутируемых тем;

- факты эмоциональных высказываний и переходов на личности.

При анализе презентаций проектов (презентации для открытия, статуса или закрытия проекта) обращалось внимание на идентифицированные риски проекта и значимые события проекта, и отражение этих рисков и событий в протоколах каких-то из проектных коммуникаций. 
Анализ протоколов встреч включал в себя:

- проверку наличия протоколов встреч;

- проверку своевременности распространение протокола участникам встречи;

- соответствие повестки и протокола встречи;

- статус отслеживания и закрытия открытых вопросов, возникших на предыдущих встречах.

Признаки выявленных обструкционных приемов идентифицировались по наличию в более чем одной встрече.

Инициаторы обструкционных приемов определялись по факту первого применения приема на встрече.

Модерация определялась как попытка ведущего встречи управлять встречей для минимизации негативных последствий обструкции. Выявлялась только при прослушивании записей встреч.

Частично успешная модерация определялась по прекращению применения соответствующего обструкционного приема в момент управляющего воздействия, но с повторной попыткой обструкции тем же приемом до конца встречи.

Успешная модерация определялась по прекращению применения соответствующего обструкционного приема на оставшееся время встречи.

\section{Результаты}

В рамках работы проанализированы материалы 48 проектов, в том числе:

- Протоколы 496 встреч;

- Аудиозаписи 151 встречи;

- 177 презентаций;

- 52 протокола lessons learned и рефлексий.

Проведены 39 интервью с участниками встреч.

В результате проведенной работы выявлены 35 факторов недружественного поведения участников (приемы обструкции) коммуникаций, которые приводили к срывам встреч или договоренностей на том или ином промежутке времени:

1. Недостоверная повестка. Повестка встречи отсутствует или не соответствует предмету встречи.

2. Некорректная аудитория. Состав участников встречи недостаточен или не имеет отношения к вопросам, которые предполагается обсуждать на встрече.

3. Затягивание времени. Уклонение от обсуждения сложных или спорных вопросов, уклонение от представления отсутствующих или недостаточных результатов работ.
4. Противоположная задача. У ряда участников выявляются цели и задачи строго противоположные целям и задачам команды - например, несогласные с проектом или его частью.

5. Хаотизация представлений. Стремление участника встречи к отсутствию какой-либо конкретики, абстрактным размышлениям, размытости, необоснованному усложнению.

6. Отсутствие фиксации позиции. Участник встречи не описывает свою позицию в конкретных терминах или значениях.

7. Демонизация явления или предмета. Идентифицируется по факту использования неаргументированных оценок о том, что какая-то система плоха, процесс плох, человек плох и т.п.

8. Переключение внимания. Техника проявляется в а) перепрыгивании с вопроса на вопрос в обсуждении; б) акцентировании или возвращении к ранее идентифицированному конфликтному вопросу; в) отклонении обсуждения от повестки в сторону не имеющих отношения или чересчур детализированных вопросов.

9. Рассеяние внимания. Достаточно сложная техника, проявляющаяся в идентификации болевых точек разных участников и акцентуации дискуссии на разных вопросах, представляющих существенных интерес для разных участников, отвлекая их от обсуждения целевого вопроса в рамках предполагаемой целевой модели обсуждаемого.

10. Изматывание. Часто встречаемая практика, использующая как дополнительные инструменты многословие, хаотизацию представлений. Идентифицируется как многоитерационное обсуждение одного и того же вопроса при условии отсутствия или недостаточности конкретной аргументации.

11. Намеренное многословие. Наиболее часто встречается как бесконечные монологи одного участника встречи, который старается тем самым переключить внимание на себя, либо затянуть время. Также часто совмещено с хаотизацией.

12. Забалтывание. Вариант многословия, идентифицируемый по многочисленным объяснениям уже договоренного или общеизвестного, используемый обычно совместно с хаотизацией для затягивания времени и ухода от обсуждения конкретной проблемы в конкретном контексте. Например, как забалтывание можно описать ситуацию, когда вместо обсуждения конкретной проблемы «как абонент услуги X может заплатить деньги» забалтывающий переводит обсуждение на тему «как вообще может быть изменен баланс лицевого счета».

13. Гвалт. Легко идентифицируемое состояние встречи, когда идет несколько одновременных, иногда отвлеченных, обсуждений. Часто совмещается 
с забалтыванием. Серьезный инструмент, встреча с которым требует от модератора существенных усилий по наведению порядка на встрече.

14. Словесный напор. Определяется как повышенная эмоциональность, увеличенная скорость речи, безаппеляционность суждений (вплоть до хамства), тона и оценок, заранее определенное пренебрежение к позиции других участников дискуссии, иногда и к самим участникам дискуссии.

15. Расширение объема дискуссии. Попытка объять необъятное, излишняя широта или детализация в дискуссии.

16. Провоцирование эмоций. Наиболее часто встречается как инструмент аргументации при отсутствии разумной позиции.

17. Демонизация оппонента. Один из инструментов словесного напора, который проявляется в высказывании пренебрежительного мнения об оппоненте, его деятельности, возможностях, опыте.

18. Оскорбительный стиль. Еще один достаточно сильнодействующий инструмент, позволяющий превратить практически любую дискуссию в неконструктивную.

19. Обвинение в недружественном (неконструктивном) поведении. Применяется немедленно, как только оппонент сорвался и ответил на провокацию.

20. Переход на личности. В последнее время часто встречается в опосредованном виде, например на видеоконференции, когда один из участников шарит свой экран, ему отправляются сообщения в мессенджер, характеризующие говорящего участника конференции, например «что он несет» или «какой идиот».

21. Хаотический стиль выступления. Иногда сложно сказать это прием для атаки на участников встречи или это действительно проблема со связностью изложения мыслей.

22. Односторонность рассмотрения. Техника намеренного опускания точек зрения, которые могут позволить аргументировать альтернативные выступающему мнения.

23. Вырывание из контекста. Частая техника. Очень часто применяется при обсуждении ранее конфликтных или проблемных вопросов, по которым высказывались спорные мнения.

24. Ложные аналогии.

25. Косвенные ссылки. Техника выражается, в первую очередь, в активном применении ссылок вида «всем известно что...», «мы все помним что ...» без фиксации конкретных фактов или свойств, то есть создании неопределенности восприятия.

26. Гипербола. Масштабное преувеличение отрицательных свойств системы, процесса, явления. В пределе может быть демонизацией.
27. Междусобойчики. Один из компонентов гвалта, но может существовать и отдельно, если выполняется в относительно деликатной форме. Приводит к размыванию внимания остальных участников. Достаточно просто модерируется.

28. Ложный образ. Создание некорректного образа обсуждаемой проблемы - намеренное искажение или умалчивание отдельных свойств.

29. Провоцирование скандала.

30. Обвинение в непрофессионализме.

31. Преувеличение сложности. Прием применяемый в дискуссиях, с участием недостаточно глубоко погруженных участников, которым преподносится идея о невозможности или чрезмерной сложности реализации того или иного механизма, метода, модуля.

32. Игнорирование позиции собеседника.

33. Неконструктивный стиль. Фактически совокупность ряда описанных выше методов.

34. Деактуализация повестки. Атака на повестку встречи с аргументацией о ее неактуальности.

35. Ценностный нигилизм. Нечасто встречаемый, но очень тяжелый для модерации инструмент фактическое отрицание ценностей большинства участников дискуссии. Например, если подрядчик безапелляционно декларирует заказчику, что тот не понимает что ему нужно.

Для каждого из выявленных методов недружественной коммуникации разработано определение; выявлены инициаторы недружественной коммуникации; по возможности, определены отличительные признаки, с помощью которых можно идентифицировать применяемый обструктивный метод; для некоторых из выявленных методов сформулированы рекомендованные решения.

Отмечено, что для ряда выявленных методов модерация не производилась вообще, либо не была успешной. Причины данного явления в настоящей работе не рассматриваются.

В ходе выполнения работы сделано предположение о наличии определенной связи между частотой выявления тех или иных обструкционных методов и конкретным менеджером, который вел соответствующие проекты. Причины возникновения, статистические параметры таких связей, а также корреляции со стилем управления, в настоящей работе не рассматриваются и планируются быть предметом дальнейшего исследования.

\section{Выво $\Delta ы$}

В работе представлены результаты анализа нескольких сотен коммуникаций 48 проектов одного направле- 
ния деятельности с целью выявления приемов недружественных коммуникаций, оказывающих негативное влияние на проект, что ранее не описывалось в литературе.

Впервые описана методика проведения анализа коммуникаций и анализ большой выборки коммуникаций.
Описаны исходные данные для анализа и критерии их отбора.

Выявлены наиболее часто встречающиеся методы недружественной коммуникации в проектах. Проанализированы и предложены идентификационные признаки наличия обструкционных приемов в проектных коммуникациях.

\section{ЛИТЕРАТУРА}

1. The Standish Group report. Chaos. 2011. [Электронный ресурс] // URL https://www.projectsmart.co.uk/white-papers/chaos-report.pdf. Дата обращения 01.06.2020.

2. PMl's pulse of the profession: The high cost of low performance. 2014. [Электронный ресурc] // URL https://www.pmi.org/-/media/pmi/documents/public/pdf/ learning/thought-leadership/pulse/pulse-of-the-profession-2017.pdf. Дата обращения 01.06.2020.

3. PMI's pulse of the profession. 9th Global Project management survey. 2017. [Электронный pecypc] // URL https://www.pmi.org/-/media/pmi/documents/public/ pdf/learning/thought-leadership/pulse/pulse-of-the-profession-2017.pdf. Дата обращения 01.06.2020.

4. PMl's pulse of the profession: Success in disruptive times. 2018. [Электронный ресурс] //URL https://www.pmi.org/-/media/pmi/documents/public/pdf/learning/ thought-leadership/pulse/pulse-of-the-profession-2018.pdf. Дата обращения 01.06.2020.

5. PMI' pulse of the profession: Requirements management - a core competency for Project and Program success. 2014 [Электронный pecypc] // URL https://www. pmi.org/-/media/pmi/documents/public/pdf/learning/thought-leadership/pulse/requirements-management.pdf. Дата 0бращения 01.06.2020.

6. Geneca (2011). Doomed From the Start? Why a Majority of Business and IT Teams Anticipate Their Software Development Projects Will Fail. // Geneca. Oakbrook terrace, IL.

7. The state of project management. Annual survey. 2018. [Электронный ресурс] // URL https://www.wellingtone.co.uk/wp-content/uploads/2018/05/The-Stateof-Project-Management-Survey-2018-FINAL.pdf. Дата обращения 01.06.2020.

8. Gartner survey shows why project fails. 2012. [Электронный ресурс] // URL https://thisiswhatgoodlookslike.com/2012/06/10/gartner-survey-shows-whyprojects-fail/. (Дата обращения 01.06.2020).

9. A guide to the project management body of knowledge (PMBOK guide), 6th edition. 2017/ Newton-square, PA: Project management institute, 2017.

10. The standart for project management. 2017. Newton-square, PA: Project management institute, 2017.

11. PRINCE2 [Электронный ресурc] // URL: https://www.prince2.com/eur/downloads. (Дата обращения 01.10.2020).

12. Зубков Н.А. (2018) Трансформация субъективности в коммуникативном пространстве информационного конфликта // Философские проблемы информационных технологий и киберпространства, 2018 № 2 (15).

(с Смирнов Сергей Павлович ( smirnov.s.p1@edu.mirea.ru).

Журнал «Современная наука: актуальные проблемы теории и практики» 